\title{
As percepções dos estudantes mineiros sobre a incidência de comportamentos de indisciplina em sala de aula \\ um estudo baseado nos dados do SIMAVE/PROEB 2007 *
}

\author{
LUCIANO CAMPOS DA SILVA \\ Universidade Federal de Ouro Preto, \\ Mariana, MG, Brasil \\ DANIEL ABUD SEABRA MATOS \\ Universidade Federal de Ouro Preto, \\ Mariana, MG, Brasil
}

\begin{abstract}
RESUMO
$\mathrm{O}$ artigo decorre de uma pesquisa com delineamento de survey que investigou as percepções de estudantes de escolas públicas de Minas Gerais sobre a incidência de comportamentos de indisciplina em sala de aula, analisando como alguns fatores se associam a essa percepção: nível de ensino, sexo dos estudantes, nível socioeconômico, atraso escolar, proficiência em língua portuguesa e matemática e as práticas pedagógicas dos docentes. Utilizou-se o Programa de Avaliação da Rede Pública de Educação Básica (PROEB, 2007), que faz parte do Sistema Mineiro de Avaliação da Educação Pública (SIMAVE). Participaram todos os alunos do $5^{\circ}$ ano $(\mathrm{N}=$ 307.386), do $9^{\circ}$ ano $(\mathrm{N}=251.354)$ e do $12^{\circ}$ ano $(\mathrm{N}=156.906)$. Destacaram-se como principais resultados: indisciplina em sala de aula; forte relação entre fracasso escolar e indisciplina; baixa associação entre indisciplina e nível socioeconômico; forte relação entre as práticas pedagógicas dos docentes e a indisciplina. Os resultados reforçam a centralidade da indisciplina na educação escolar.
\end{abstract}

PALAVRAS-CHAVE

indisciplina; pesquisa de survey; PROEB.

* Apoio: Universidade Federal de Ouro Preto (UFOP) e Fundação de Amparo à Pesquisa do Estado de Minas Gerais (FAPEMIG). 


\section{STUDENTS' PERCEPTIONS ABOUT THE INCIDENCE OF UNDISCIPLINED BEHAVIORS IN THE CLASSROOM: A STUDY BASED ON DATA FROM SIMAVE/PROEB 2007}

\section{ABSTRACT}

The paper derives from a survey research, which investigated the perceptions of students' from public schools of Minas Gerais about the incidence of undisciplined behaviors in the classroom and analyze the role of potential contributing factors (e.g., educational level, sex of the students, socioeconomic status, educational gap, proficiency in Portuguese and mathematics, and teachers' pedagogical practices). We used the Assessment Program of the Primary Public Education (2007) database, which is part of the Public Education Assessment System of Minas Gerais (SIMAVE). Students enrolled in the 5 th year $(\mathrm{N}=307.386), 9$ th year $(\mathrm{N}=251.354)$, and 12 th year $(\mathrm{N}=156.906)$ of schooling participated. Highlight results include: undisciplined behaviors in the classroom; there was a strong relationship between indiscipline and teachers' pedagogical practices and academic failure; while there was a weak association between indiscipline and socioeconomic status. The results reinforce the centrality of indiscipline in education.

\section{KEYWORDS}

indiscipline; survey research; PROEB.

\section{LAS PERCEPCIONES DE LOS ESTUDIANTES MINEIROS SOBRE LA INCIDENCIA DE LOS COMPORTAMIENTOS DISRUPTIVOS EN CLASE: UN ESTUDIO BASADO EN DATOS DE SIMAVE/PROEB 2007}

\section{RESUMEN}

$\mathrm{El}$ artículo es fruto de una investigación que utiliza survey, la cual investigó las percepciones de los estudiantes de escuelas públicas de Minas Gerais respecto a las incidencias de los comportamientos disruptivos en el aula y analizó cómo ciertos factores se asocian con conductas disruptivas: el nivel de enseñanza, el sexo de los estudiantes, el nivel socioeconómico, la brecha educacional, la competencia en lengua portuguesa y en matemáticas y las prácticas pedagógicas de los maestros. Utilizamos el Programa de Evaluación de la Educación Pública Básica (2007), que es una parte del Sistema Mineiro de Evaluación de la Educación Pública (SIMAVE). Participaron todos los estudiantes del $5^{\circ}$ año $(\mathrm{N}=307.386)$, del $9^{\circ}$ año $(\mathrm{N}=251.354)$ y del $12^{\circ}$ año $(\mathrm{N}=156.906)$. Las principales conclusiones son: conductas disruptivas en el aula; fuerte relación entre el fracaso escolar y la indisciplina, asociación baja entre las conductas disruptivas y el nivel socioeconómico; fuerte relación entre las prácticas pedagógicas de los docentes y la indisciplina. Los resultados refuerzan la influencia de la indisciplina en la educación escolar.

PALABRAS CLAVE

indisciplina, estudio de survey; PROEB. 


\section{INTRODUÇÃO}

As expressões "sucesso" e "fracasso" escolar, comumente empregadas na literatura educacional para indicar índices de desempenho, aprovação ou reprovação, evasão ou permanência, podem assumir sentidos variados se tomarmos como referência outras finalidades, além da aquisição de conhecimento, dos sistemas de ensino ou das escolas (Pires, 1985).

Embora a transmissão do conhecimento esteja no cerne do trabalho desenvolvido pelas escolas, não há como negar que estas têm desempenhado historicamente uma importante função de socialização. Não há escola que não inclua entre seus objetivos educativos a preparação das crianças e adolescentes para a vida em sociedade. Assim, se flexibilizarmos as expressões "sucesso" e "fracasso" escolar, poderemos falar em um novo campo de fracasso escolar: o fracasso na socialização dos estudantes.

Se o fracasso na socialização dos estudantes não aparece com muita frequência nas estatísticas educacionais é porque, por um lado, isso impõe a construção rigorosa de índices para medi-lo e, por outro, porque a função de instrução é colocada como finalidade fundamental das escolas. Isso acaba conferindo menor importância à produção de indicadores que evidenciem outras formas de fracasso escolar (Afonso, 1988).

No presente trabalho, analisamos um fenômeno que pode ser considerado como um dos maiores indicadores do fracasso na socialização escolar: a indisciplina. Para Aquino (1996, p. 7), "há muito os distúrbios disciplinares deixaram de ser um evento esporádico e particular no cotidiano das escolas brasileiras para se tornarem, talvez, um dos maiores obstáculos pedagógicos dos dias atuais". Isso significa que a indisciplina na escola, além de se configurar como um indicador do fracasso no trabalho de socialização dos estudantes, pode ainda funcionar como uma forte perturbadora do processo de ensino-aprendizagem.

Dado que a relação pedagógica constitui-se como uma relação de caráter intersubjetivo, mesmo que a transmissão de conhecimento seja colocada como o objetivo fundamental da escolarização, ela jamais pode ser isolada das relações humanas e do ambiente psicossocial em que ocorre. Como lembra Onetto (2003), quando as relações humanas que se desenvolvem nas escolas não se efetuam com base em parâmetros de bem-estar psicológico, ético e emocional, torna-se quase impossível ensinar ou aprender.

Assim, apesar da sua grande relevância pedagógica, o fenômeno da indisciplina ainda tem sido pouco explorado por pesquisas acadêmicas (Szenczuk,2004).Isso ocorre também no campo da sociologia da educação. De fato, haveria uma tendência a considerar a indisciplina como um problema de ordem mais prática do que teórica, fato que explicaria o predomínio de abordagens tradicionalmente mais normativas na análise do fenômeno, como algumas tendências do campo da psicologia (Afonso,1991; Roure, 2001). Esse tímido interesse dos sociólogos pelo tema surpreende por dois motivos. Em primeiro lugar porque a indisciplina é considerada um objeto sociológico relevante já em obras fundadoras da sociologia da educação (Durkheim). Em segundo lugar, o tema apresenta um enorme potencial para esclarecer problemas teóricos na observação e descrição dos comportamentos sociais (Afonso, 1991).

Nesse sentido, a presente pesquisa contribui para o alargamento do debate acadêmico sobre a indisciplina. Seu objetivo é investigar as percepções dos estudantes 
de escolas públicas de Minas Gerais sobre a incidência de comportamentos de indisciplina em sala de aula e analisar o modo como alguns fatores se associam à percepção da indisciplina: nível de ensino, sexo dos estudantes, nível socioeconômico (NSE), atraso escolar, proficiência em língua portuguesa e matemática, além de práticas pedagógicas dos professores (níveis de exigência, interesse e abertura em relação aos alunos). Para isso, utilizamos os dados do Programa de Avaliação da Rede Pública de Educação Básica (PROEB) do ano de 2007.

\section{O CONCEITO DE INDISCIPLINA NA EDUCAÇÃO}

Nos últimos anos, com o agravamento da violência escolar e a enorme visibilidade social que ela tem adquirido, tornou-se bastante comum a existência de confusões envolvendo o uso dos conceitos de indisciplina e violência no meio educacional. Empregado correntemente, até aproximadamente a década de 1980, para designar os vários comportamentos perturbadores que põem em causa as regras no ambiente escolar, atualmente o conceito de indisciplina tem se tornado pouco eficaz para descrever e interpretar alguns comportamentos disruptivos mais graves que atingem as escolas. Por isso, esses comportamentos têm sido frequentemente analisados sob a designação de "violência escolar".

Entretanto, conforme denunciam alguns autores, existiria no meio educacional uma forte tendência a abandonar o uso do conceito clássico de indisciplina em favor de uma designação mais genérica dos diversos comportamentos que põem em causa as regras no ambiente escolar como "atos de violência" (Amado, 2004; Prairat, 2003). Certamente tem contribuído para isso o fato de que condições políticas e sociais específicas - como o reconhecimento dos direitos sociais e o aumento do exercício da cidadania pelos sujeitos - fizeram com que o conceito de violência sofresse um alargamento considerável. Isso faz com que ele tenda a englobar comportamentos que antes eram percebidos como práticas banais no mundo social. Por isso, tem sido frequente no meio educacional a discussão em torno da pertinência de empregar o conceito de violência escolar de uma forma demasiadamente ampliada, fazendo com que ele seja facilmente confundido ou acabe incorporando o conceito de indisciplina.

Autores como Prairat (2003) têm criticado firmemente esse uso alargado do conceito de violência, defendendo que ele deveria se limitar aos atos previstos pelo código penal. Esse autor denuncia um processo de colonização do discurso pedagógico atual pelo conceito de violência, a ponto de "eclipsar" o conceito clássico de indisciplina, chamando a atenção para os riscos políticos, epistemológicos e educativos de uma definição muito ampliada do conceito de violência escolar.

Entre esses diversos riscos, destaca-se o perigo real de criminalizar comportamentos escolares triviais e de pouca gravidade, o uso frequente e a princípio desnecessário das forças policiais na resolução de conflitos eminentemente escolares e a destituição de importância pedagógica, social e científica dos comportamentos típicos de indisciplina. Comportamentos que, embora causem pouca comoção pública e sejam aparentemente inofensivos, teriam forte impacto sobre o clima escolar, a socialização e a aprendizagem 
dos estudantes. Em contrapartida, não faltam investigadores que apontam justamente o perigo inverso de "mascaramento" dos atos de violência, denunciando, entre outros fatores, o fato de eles serem frequentemente confundidos ou camuflados como atos de indisciplina (Camacho, 2001).

Em face desses perigos, no Brasil, autores como Silva e Nogueira (2008), mesmo admitindo a existência de semelhanças entre esses dois fenômenos, têm defendido a possibilidade e a necessidade atual de uma distinção mais precisa entre os conceitos de indisciplina e violência escolar de modo que se consiga clarificar melhor os tipos de comportamento que eles descrevem e abrangem. Em defesa desse argumento, enfatizam que a análise acurada da literatura acadêmica sobre os dois fenômenos indica a possibilidade de se diferenciá-los com base em comparação de algumas de suas características específicas: tipo de regras que violam, impacto que geram no ambiente escolar e nos sujeitos e gravidade intrínseca que comportam.

Nesse sentido, os autores argumentam que a indisciplina seria frequentemente associada aos comportamentos disruptivos menos graves, que violam regras estritamente escolares e que, por isso, não gerariam danos imediatos aos sujeitos. Seriam comportamentos que, conforme dizem os próprios professores, burlariam as regras escolares, dificultando o "bom andamento da aula". Em certos casos, esses comportamentos chegariam mesmo a questionar diretamente a autoridade dos docentes.

São exemplos de comportamentos inventariados por pesquisas nacionais e internacionais que investigam esse fenômeno: as conversas clandestinas, os gritos e deslocamentos não autorizados em sala de aula, as brincadeiras perturbadoras, as desobediências às ordens dos professores e as réplicas às suas ações disciplinadoras. Comportamentos que tenderiam a ser caracterizados como atos de indisciplina por violarem regras escolares consideradas pelas instituições e pelos professores como fundamentais para a manutenção das condições de convívio e de trabalho em sala de aula.

Por apresentarem pouca gravidade intrínseca, esses comportamentos seriam condenados mais por causa da perturbação que geram no ambiente escolar que pelas consequências imediatas que poderiam acarretar à integridade física ou psicológica dos sujeitos. Por isso, desde que não sejam frequentes, tendem a ser ignorados pelos professores. Daí que, como ressalta Silva (2007), dentro de certas circunstâncias, desde que facilmente controlados pelos professores, os comportamentos de indisciplina podem, até mesmo, contribuir para a vitalidade de uma turma, ao descontraírem os alunos e desfazerem a forte tensão e cansaço gerados pela rotina escolar. É, portanto, à medida que se tornam demasiadamente frequentes que os comportamentos de indisciplina passam a assumir maior gravidade, perturbando a relação pedagógica e impedindo que a aula transcorra em clima de tranquilidade.

Já a violência escolar tem sido frequentemente associada a eventos disruptivos de natureza grave, que feririam regras sociais mais abrangentes e que teriam a capacidade de causar danos físicos, morais, psicológicos ou materiais às pessoas ou às instituições que deles são alvos. Assim, embora os autores citados reconheçam que permanece aberta na comunidade científica a discussão em torno de uma definição precisa do conceito de violência escolar, até mesmo em razão da multiplicidade dos eventos que têm sido 
considerados violentos pelos atores sociais, enfatizam que a ampla maioria dos estudos sobre essa temática tende a apontar a existência do poder destrutivo, da coerção, do uso da força física e das figuras do agressor e/ou da vítima como elementos consensuais que caracterizariam um dado comportamento como sendo de violência.

Esse é o caso dos assassinatos, dos roubos, do porte de armas, do tráfico de drogas, das ameaças, das agressões físicas ou psicológicas, comportamentos que, devido a sua enorme gravidade intrínseca, são fortemente condenados e penalizáveis em todas as esferas da vida social, e não somente nas escolas. Em muitos casos, os comportamentos comumente designados como atos de violência escolar poderiam facilmente ser enquadrados como crimes - quando protagonizados por adultos - ou como atos infracionais - quando protagonizados por adolescentes.

Neste trabalho, usamos o conceito de indisciplina para designar aqueles comportamentos que violam regras estritamente escolares, as quais buscam de modo mais imediato garantir as condições necessárias à realização do trabalho pedagógico. Esse conceito certamente inclui alguns comportamentos que violam normas sociais mais gerais, de fundo ético-social e que servem para regular a convivência entre os sujeitos no ambiente escolar. Contudo, tais comportamentos não chegam a atingir o foro da violência, uma vez que não se observa neles qualquer intenção de causar danos materiais aos sujeitos ou alguma capacidade de atingi-los em sua integridade física, psicológica ou moral.

\section{MÉTODO}

\section{DESENHO DE PESQUISA, SIMAVE E CARACTERIZAÇÃO DOS SUJEITOS}

Esta pesquisa teve um delineamento de survey. Esse tipo de delineamento envolve procedimentos em pesquisa quantitativa, na qual se aplica um questionário em uma amostra ou em uma população inteira para descrever atitudes, opiniões, comportamentos ou características da população. Após a coleta de dados, o pesquisador realiza análises estatísticas para descrever tendências nas respostas das questões e testar problemas de pesquisa ou hipóteses. Ele também interpreta o significado dos dados relacionando os resultados dos testes estatísticos com estudos anteriores (Creswell, 2005).

As técnicas estatísticas utilizadas neste trabalho foram: estatística descritiva (medidas de tendência central e medidas de dispersão), correlação e uma técnica estatística multivariada chamada Teoria da Resposta ao Item (TRI). Todos esses métodos se mostram adequados para organizar, descrever e sumarizar dados de grandes coletivos de indivíduos.

Foram utilizados os dados provenientes do PROEB (2007), uma modalidade de avaliação em larga escala que faz parte do Sistema Mineiro de Avaliação da Educação Pública (SIMAVE). O PROEB avalia a proficiência dos estudantes dos $5^{\circ}, 9^{\circ}$ e $12^{\circ}$ anos das escolas públicas mineiras em matemática e língua portuguesa. Paralelamente são aplicados questionários contextuais aos estudantes, professores e diretores com o 
objetivo de coletar informações gerais sobre suas características socioculturais, o ambiente escolar e as práticas pedagógicas desenvolvidas pelas escolas e pelos professores.

Uma vez que o questionário contextual aplicado aos estudantes contém alguns itens que abordam as percepções dos discentes sobre a incidência de comportamentos de indisciplina, esse instrumento constitui-se como uma fonte valiosa de investigação sobre esse fenômeno, sobretudo quando se considera o volume de estudantes participantes da pesquisa (como o PROEB tem caráter censitário, não se trata de uma amostra, mas sim do universo de alunos do estado de Minas Gerais). Dessa forma, participaram da avaliação todos os estudantes do $5^{\circ}$ ano $(\mathrm{N}=307.386)$, do $9^{\circ}$ ano $(\mathrm{N}=251.354)$ e do $12^{\circ}$ ano $(\mathrm{N}=156.906)$, totalizando 715.646 alunos.

\section{VARIÁVEIS ANALISADAS E ELABORAÇÃO DE ÍNDICES}

Nesta pesquisa, buscamos relacionar a percepção de indisciplina com as seguintes variáveis: nível de ensino, sexo dos estudantes, nível socioeconômico, atraso escolar (número de repetências), proficiência em língua portuguesa e matemática e práticas pedagógicas dos professores (exigência do professor; interesse e compromisso do professor; abertura e disponibilidade do professor). Destacamos que todos os dados deste trabalho foram retirados da versão para os estudantes do questionário do PROEB. Portanto, mesmo as práticas pedagógicas dos professores foram obtidas por meio das percepções dos alunos.

Passamos agora a descrever as questões utilizadas no questionário para a obtenção dos dados, mais especificamente com relação à indisciplina, práticas pedagógicas dos professores e nível socioeconômico (Quadro 1).

\section{Quadro 1 - Questões utilizadas no questionário}

\begin{tabular}{|c|c|}
\hline Variável & Questões \\
\hline \multirow{3}{*}{ Indisciplina } & $\begin{array}{l}\text { 24- Com que frequência o }(\mathrm{a}) \text { professor(a) tem que esperar } \\
\text { muito tempo até que os alunos façam silêncio? }\end{array}$ \\
\hline & 33- Com que frequência há barulho e desordem na sala de aula? \\
\hline & 35- Com que frequência os alunos saem de sala antes do término das aulas? \\
\hline \multirow{2}{*}{ Exigência do professor } & $\begin{array}{l}25 \text { - Com que frequência o(a) professor(a) exige que os } \\
\text { alunos estudem e prestem atenção nas aulas? }\end{array}$ \\
\hline & $\begin{array}{l}26 \text { - Com que frequência o(a) professor(a) exige que } \\
\text { os trabalhos dos alunos sejam bem feitos? }\end{array}$ \\
\hline \multirow{3}{*}{$\begin{array}{l}\text { Interesse e compromisso } \\
\text { do professor }\end{array}$} & $\begin{array}{l}\text { 27- Com que frequência o(a) professor(a) mostra } \\
\text { interesse no aprendizado de todos os alunos? }\end{array}$ \\
\hline & $\begin{array}{l}30 \text { - Com que frequência o(a) professor(a) continua a } \\
\text { explicar até que todos os alunos entendam a matéria? }\end{array}$ \\
\hline & 31 - Com que frequência o(a) professor(a) se esforça para ajudar os alunos? \\
\hline \multirow{2}{*}{$\begin{array}{l}\text { Abertura e } \\
\text { disponibilidade } \\
\text { do professor }\end{array}$} & $\begin{array}{l}28 \text { - Com que frequência o(a) professor(a) dá oportunidade } \\
\text { de os alunos expressarem suas opiniões? }\end{array}$ \\
\hline & $\begin{array}{l}29 \text { - Com que frequência o(a) professor(a) está disponível } \\
\text { para esclarecer as dúvidas dos alunos? }\end{array}$ \\
\hline
\end{tabular}

(continua...) 
(...continuação)

\begin{tabular}{|ll|}
\hline \multicolumn{1}{|c|}{ Variável } & \multicolumn{1}{c|}{ Questões } \\
\hline & Quantos dos seguintes itens abaixo há no lugar onde você mora? \\
& 1. Banheiro \\
2. Televisão em cores & 3. Videocassete \\
4. Rádio & 5. Geladeira \\
6. Freezer & 7. Máquina de lavar roupa \\
Nível socioeconômico Aspirador de pó & 9. Automóvel \\
& 10. Possui DVD \\
11. Em sua casa trabalha alguma empregada doméstica? & 12. Sua família recebe bolsa-família? \\
13. Além dos livros escolares, quantos livros há em sua casa? & 14. Em sua casa tem computador? \\
\hline
\end{tabular}

Fonte: Baseado nos dados do PROEB (2007).

Elaboração dos autores.

No Quadro 1, o formato de resposta das questões de indisciplina e de práticas pedagógicas dos professores é uma escala Likert de quatro pontos: $(1=$ nunca; $2=\mathrm{em}$ algumas aulas; $3=$ na maioria das aulas; $4=$ em todas as aulas). Embora os questionários contextuais do PROEB não tenham sido construídos com o propósito específico de investigar a indisciplina, o que pressuporia a inclusão de questões sobre os diferentes tipos de indisciplina, constata-se que os três itens constantes no instrumento medem pelo menos três formas de comportamento discente frequentemente associadas pela literatura como sendo atos típicos de indisciplina (Amado, 1998).

As questões 24 e 33 abordam os chamados "desvios às regras da comunicação na sala de aula", identificados como sendo os tipos de indisciplina mais comuns nas escolas. Nessa categoria situam-se comportamentos como conversar, gritar e fazer barulhos durante as aulas. Já a questão 35 aborda um dos tipos específicos de "desvios às regras da mobilidade na sala aula": as saídas não autorizadas de sala. Portanto, todas as interpretações feitas nessa pesquisa com relação à indisciplina se limitam aos tipos desse fenômeno abordados nessas três questões.

Considerando que raramente é possível chegar a um único item que represente bem uma variável ou um construto complexo, uma solução possível para esse problema é a construção de índices. Os índices são elaborados com a combinação de vários itens do questionário, o que evita o efeito de viés inerente aos itens individuais. Assim, os índices são considerados como dispositivos de redução dos dados, pois várias respostas podem ser resumidas em um único resultado (Babbie, 1999). Dessa forma, elaboramos índices para todas as variáveis do Quadro 1.

Os índices de indisciplina e das práticas pedagógicas dos professores foram calculados pela média das respostas de cada aluno para cada uma das variáveis. Por exemplo: o índice de indisciplina foi calculado tomando-se por base média as respostas do aluno para 
as questões 24,33 e 35. A mesma lógica se aplica às práticas pedagógicas dos professores. Todos esses índices podem variar entre 1 e 4 . No entanto, quanto maior o valor do índice de indisciplina, mais negativa é a percepção do aluno (ou seja, ocorre maior incidência de comportamentos de indisciplina). Já no caso das práticas pedagógicas dos docentes, ocorre o contrário: quanto maior o valor do índice, mais positiva é a percepção do aluno (ou seja, o professor mostra ser mais interessado, aberto e exigente com relação aos alunos).

Destacamos ainda que em nossas análises esses índices foram utilizados tanto no nível do aluno (exemplo: resposta de todos os estudantes do $5^{\circ}$ ano, estando as interpretações dos resultados apenas no nível do aluno) quanto no nível da escola (exemplo: índice de indisciplina agrupado por escola, o que significa a média dos índices de todos os alunos daquela escola). Isso também se aplica às outras variáveis analisadas. Por exemplo: tendo como unidade de análise a escola, podemos correlacionar a média de indisciplina da escola com a proficiência média em matemática da escola.

Ainda com relação ao índice de indisciplina, em alguns casos criamos uma estratégia de classificação por faixas da seguinte forma: percepção baixa de indisciplina (índice variando entre 1 e 2); percepção média de indisciplina (índice variando entre 2,01 e 3); percepção alta de indisciplina (índice variando entre 3,01 e 4). Com esse recurso podemos, por exemplo, comparar a proficiência média das escolas pertencentes às diferentes faixas de indisciplina (baixa, média e alta).

Por fim, também elaboramos um índice para o nível socioeconômico, que foi construído com base nos itens do questionário do estudante sobre o conforto doméstico (bens de consumo, presença de empregada doméstica) e o benefício da bolsa-família (que melhora a inferência sobre a renda familiar). A escolaridade dos pais não está incluída no questionário. Essa dimensão é medida indiretamente por meio de itens associados ao nível cultural da família (Alves, 2011). O Quadro 1 apresenta as questões utilizadas para a elaboração do índice do nível socioeconômico.

O nível socioeconômico é considerado como um construto latente (não pode ser observado diretamente). Portanto, devem ser utilizadas técnicas estatísticas apropriadas para medir esse tipo de construto. Nesta pesquisa, utilizamos a TRI (Embretson; Reise, 2000). Essa técnica vem sendo mais utilizada em pesquisas sociais para a construção de variáveis latentes como o nível socioeconômico, apesar de já ser bastante aplicada para a análise da proficiência de estudantes em testes cognitivos (Alves; Soares, 2009). O objetivo principal da TRI é obter medidas de construtos latentes por meio de indicadores ordinais ou dicotômicos. Neste trabalho, utilizamos o modelo de Semejima, que é considerado o mais adequado para itens com respostas graduadas (Alves, 2011).

\section{RESULTADOS}

A análise das percepções dos estudantes indica uma presença marcante dos comportamentos de indisciplina em sala de aula. A maior incidência de indisciplina foi encontrada nas questões 24 e 33 . Por exemplo: no $5^{\circ}$ ano, $51,5 \%$ dos discentes afirmaram que seus professores têm de esperar muito tempo até que os alunos façam silêncio em 
sala, na maioria ou em todas as aulas. Já no $9{ }^{\circ}$ ano, $42,6 \%$ dos estudantes apontaram que há barulho e desordem na sala, na maioria ou em todas as aulas.

Em relação à questão 35, foram encontrados percentuais menos expressivos. Por exemplo, $20,2 \%$ dos alunos do $12^{\circ}$ ano afirmaram que, na maioria ou em todas as aulas, seus colegas saem de sala antes do término das aulas. Esse resultado está de acordo com o esperado na literatura (esse tipo de indisciplina tem se mostrado menos frequente). Contudo, as saídas não autorizadas dos estudantes de sala de aula costumam indicar a existência de uma enorme fragilidade das regras escolares, uma vez que só ocorrem em contextos em que o estudante desconsidera completamente a autoridade do professor (Silva, 2007).Portanto, mesmo com menor frequência, esse tipo de indisciplina assume uma enorme relevância na escola.

Como já afirmamos anteriormente, existe uma série de limitações no trabalho com itens isolados. Assim, o Quadro 2 mostra os índices de indisciplina considerando todos os alunos dos anos investigados.

Quadro 2-Índice de indisciplina por ano

\begin{tabular}{|c|c|c|c|}
\hline & $\mathbf{5}^{\mathbf{0}}$ ano & $\mathbf{9}^{\mathbf{0}}$ ano & $\mathbf{1 2}^{\mathbf{0}}$ ano \\
\hline $\mathrm{M}^{*}$ & 2.35 & 2.31 & 2.29 \\
\hline $\mathrm{DP}^{* * *}$ & .74 & .64 & .63 \\
\hline
\end{tabular}

Fonte: Baseado nos dados do PROEB (2007).

Elaboração dos autores.

* M = média

** $\mathrm{DP}=$ desvio padrão

Como apontado no Quadro 2, a percepção média de indisciplina dos estudantes diminui à medida que se avança nos anos. Também merece destaque a diminuição na variabilidade das percepções no decorrer dos anos (diminuição do desvio padrão). Embora esses dados pareçam indicar uma menor incidência do fenômeno entre os alunos mais velhos, é preciso ter cautela, pois o questionário do PROEB não aborda todos os tipos de manifestação de indisciplina possíveis.

Para Estrela (1992), a idade e o nível de ensino dos estudantes influenciam significativamente nos tipos de indisciplina presentes em sala de aula. Assim, enquanto as condutas relacionadas à obstrução das "condições de produção na sala de aula" (que contemplam alguns dos tipos de indisciplina abordados no PROEB) seriam mais frequentes entre os alunos mais jovens, as condutas relacionadas à contestação direta da autoridade docente seriam mais frequentes entre os alunos mais velhos. Além disso, é preciso levar em consideração que, no decorrer dos anos, a quantidade de meninas vai se tornando cada vez maior (ver Quadro 3). Isso poderia explicar a existência de uma percepção menos acentuada de indisciplina no $9^{\circ} \mathrm{e} 12^{\circ}$ anos, uma vez que as pesquisas tendem a constatar que os meninos se envolveriam mais frequentemente que as meninas em situações de indisciplina (idem).

Ainda com relação à comparação dos alunos por sexo, o Quadro 3 apresenta a percepção de meninos e meninas do $5^{\circ}, 9^{\circ}$ e $12^{\circ}$ anos. 
Quadro 3 - Comparação do índice de indisciplina com base no sexo dos alunos

\begin{tabular}{|l|l|c|c|c|}
\hline \multicolumn{1}{|c|}{ Sex0 } & & $\mathbf{5}^{\mathbf{0}}$ ano & $\mathbf{9}^{\mathbf{0}}$ ano & $\mathbf{1 2}^{\mathbf{0}}$ ano \\
\hline \multirow{2}{*}{ Masculino } & $\mathrm{M}^{*}$ & 2.39 & 2.31 & 2.28 \\
& $\mathrm{~N}^{* *}$ & 140.244 & 105.480 & 54.252 \\
\hline \multirow{2}{*}{ Feminino } & $\mathrm{M}$ & 2.30 & 2.30 & 2.30 \\
& $\mathrm{~N}$ & 137.874 & 117.896 & 76.160 \\
\hline Teste T & & $30.50^{* * *}$ & $2.86^{*}$ & $-4.25^{*}$ \\
\hline
\end{tabular}

Fonte: Baseados nos dados do PROEB (2007).

Elaboração dos autores.

* $\mathrm{M}=$ média

** $\mathrm{N}=$ amostra

**** $\mathrm{p}<0.000$

Como indicado no Quadro 3, houve uma diferença estatisticamente significante entre a percepção média de indisciplina de meninos e meninas em todos os anos analisados (ver valores do teste T). Mais especificamente, no $5^{\circ}$ e no $9^{\circ}$ anos as meninas perceberam menos indisciplina em sala de aula. Esse resultado é similar a estudos anteriores que mostram as mulheres com uma percepção mais positiva do ambiente de aprendizagem da sala de aula do que os homens (Khine; Fisher, 2003). Já no $12^{\circ}$ ano, essa percepção se inverte (os meninos perceberam menos indisciplina), não sendo essa percepção a esperada, de acordo com a literatura.

Com o objetivo de comparar o índice de indisciplina com base no número de repetência dos alunos, elaboramos o Quadro 4.

\section{Quadro 4 - Índice de indisciplina e repetência}

\begin{tabular}{|l|c|r|r|r|r|r|}
\hline \multicolumn{1}{|c|}{ Repetência } & \multicolumn{2}{|c|}{$\mathbf{5}^{\mathbf{0}}$ ano } & \multicolumn{2}{c|}{$\mathbf{9}^{\mathbf{0}}$ ano } & \multicolumn{2}{c|}{$12^{\mathbf{0}}$ ano } \\
\hline & $\mathrm{M}$ & $\mathrm{N}$ & $\mathrm{M}$ & $\mathrm{N}$ & $\mathrm{M}$ & $\mathrm{N}$ \\
\hline Nenhuma vez & 2.31 & 192.962 & 2.27 & 144.647 & 2.27 & 91.635 \\
\hline Uma vez & 2.42 & 53.868 & 2.35 & 50.678 & 2.33 & 24.632 \\
\hline Duas vezes & 2.42 & 22.011 & 2.38 & 20.983 & 2.37 & 9.720 \\
\hline Três ou mais vezes & 2.48 & 10.695 & 2.43 & 7.326 & 2.41 & 4.174 \\
\hline
\end{tabular}

Fonte: Baseado nos dados do PROEB (2007).

Elaboração dos autores.

Os resultados do Quadro 4 mostram que a indisciplina encontra-se fortemente associada à experiência de reprovação. A percepção média de indisciplina aumenta sistematicamente em todos os anos na medida em que o número de reprovações se torna maior, e as diferenças mais significativas foram encontradas entre os estudantes que nunca foram reprovados e aqueles que já foram reprovados por três ou mais vezes.

A associação entre fracasso escolar e indisciplina (ou a percepção de indisciplina) também foi objeto de discussão no meio acadêmico em outras pesquisas. Amado (2001), por exemplo, enfatiza que a indisciplina tem sido sugerida por diversos autores como uma espécie de alternativa muitas vezes seguida por aqueles alunos que não apresentam um bom desempenho escolar. $\mathrm{O}$ autor argumenta que a indisciplina seria uma forma de o 
aluno em situação de fracasso escolar remediar as ameaças a sua autoestima,invertendo a seu modo os valores que lhe são propostos pela escola.

Além disso, consideramos a hipótese de que a associação entre indisciplina e repetência seja reforçada pelos métodos de enturmação adotados em muitas escolas. $\mathrm{O}$ uso do atraso escolar e do comportamento disciplinar como critérios de enturmação pode produzir verdadeiros "guetos" que servem de abrigo aos alunos repetentes e indisciplinados.

Ainda com relação à associação entre fracasso escolar e indisciplina, o Quadro 5 apresenta dados sobre a proficiência dos alunos em língua portuguesa e matemática. A partir daqui, todos os resultados apresentados têm como unidade de análise a escola (ou seja, os dados foram agregados por escola). ${ }^{1}$

Quadro 5 - Proficiência dos alunos e faixas de indisciplina

\begin{tabular}{|c|c|c|c|c|c|c|c|}
\hline \multirow{2}{*}{\multicolumn{2}{|c|}{$\begin{array}{c}\text { Faixas de } \\
\text { percepção de } \\
\text { indisciplina }\end{array}$}} & \multicolumn{2}{|c|}{$5^{0}$ ano } & \multicolumn{2}{|c|}{$9^{\circ}$ ano } & \multicolumn{2}{|c|}{$12^{\circ}$ ano } \\
\hline & & $\begin{array}{c}\text { Língua } \\
\text { portuguesa }\end{array}$ & Matemática & $\begin{array}{c}\text { Língua } \\
\text { portuguesa }\end{array}$ & Matemática & $\begin{array}{c}\text { Língua } \\
\text { portuguesa }\end{array}$ & Matemática \\
\hline \multirow{2}{*}{ Baixa } & $\mathrm{M}$ & 204,46 & 218,44 & 248,54 & 264,48 & 278,50 & 293,13 \\
\hline & $\mathrm{N}$ & 211 & 211 & 226 & 226 & 182 & 182 \\
\hline \multirow{2}{*}{ Média } & $\mathrm{M}$ & 191,55 & 201,35 & 237,77 & 246,91 & 271,13 & 278,84 \\
\hline & $\mathrm{N}$ & 3.055 & 3.058 & 2.442 & 2.446 & 1.310 & 1.309 \\
\hline \multirow{2}{*}{ Alta } & $\mathrm{M}$ & 160,27 & 158,24 & 223,76 & 215,10 & - & - \\
\hline & $\mathrm{N}$ & 16 & 15 & 5 & 5 & - & - \\
\hline
\end{tabular}

Fonte: Baseado nos dados do PROEB (2007).

Elaboração dos autores.

* no $12^{\circ}$ ano não houve escolas na faixa alta.

Como apontado no Quadro 5, a proficiência média das escolas diminui sistematicamente em todos os anos à medida que a percepção de indisciplina se torna mais alta. As diferenças maiores foram encontradas em matemática. No $5^{\circ}$ ano, por exemplo, a diferença entre a proficiência média das escolas situadas na faixa baixa e aquelas situadas em uma faixa média de indisciplina é de 12,91 pontos em língua portuguesa e de 17,09 em matemática. Essas diferenças se tornam ainda mais significativas quando comparamos escolas situadas na faixa baixa e alta de indisciplina. Embora poucas instituições se encontrem na faixa alta, elas exemplificam o impacto da indisciplina sobre a aprendizagem dos alunos em contextos em que as regras escolares estão extremamente fragilizadas. No $5^{\circ}$ ano, a diferença entre a proficiência média das escolas situadas na faixa baixa e na alta de percepção de indisciplina é de 44,19 pontos em língua portuguesa e de 60,2 em matemática.

Para explicar o significado dessas diferenças, utilizamos a interpretação pedagógica dos resultados em língua portuguesa do $5^{\circ}$ ano do Boletim Pedagógico do

1 Esclarecemos que escolas nas quais menos de trinta alunos responderam ao questionário foram excluídas das análises. Procedemos dessa forma para evitar inferências baseadas em um número muito pequeno de estudantes das escolas. 
PROEB como exemplo. Esse instrumento propõe uma escala de interpretação dividida em nove perfis de leitores: alfabetizando (abaixo de 100), leitor rudimentar (100 a 125), leitor iniciante (125 a 175), leitor ativo 1 (175 a 200), leitor ativo 2 (200 a 225), leitor interativo 1 (225 a 250), leitor interativo 2 ( 250 a 275), leitor interativo 3 (275 a 325) e proficiente (acima de 325). O perfil leitor iniciante representa um nível baixo de desempenho, os perfis ativo 1 e 2 representam um nível intermediário e o perfil leitor interativo 1 representa um nível recomendado. Assim, os resultados do Quadro 5 são significativamente favoráveis às escolas situadas na faixa baixa de percepção de indisciplina, cujos estudantes podem ser considerados em média leitores ativos 2 (apenas um nível abaixo do esperado).Já os resultados das escolas situadas na faixa alta de percepção de indisciplina indicam a existência de alunos considerados em média leitores iniciantes (três níveis abaixo do esperado).

Por fim, discutimos a correlação entre proficiência, nível socioeconômico, indisciplina e as práticas pedagógicas dos professores (agregados por escola) (Quadro 6).

Quadro 6-Matriz de correlação

\begin{tabular}{|c|c|c|c|c|c|c|c|}
\hline \multicolumn{8}{|c|}{$5^{\circ}$ ano } \\
\hline & $L P$ & MAT & NSE & Indisci & Exige & Intere & Abert \\
\hline LP & 1 & $.89^{*}$ & $.44^{*}$ & $-.37^{*}$ & $.32 *$ & $.33^{*}$ & $.33^{*}$ \\
\hline Mat & & 1 & $.37^{*}$ & $-.42^{*}$ & $.34^{*}$ & $.37^{*}$ & $.34^{*}$ \\
\hline NSE & & & 1 & .03 & $.05^{*}$ & $-.05^{*}$ & $.06^{*}$ \\
\hline Indisci & & & & 1 & $-.33^{*}$ & $-.40^{*}$ & $-.35^{*}$ \\
\hline Exige & & & & & 1 & $.65^{*}$ & $.59^{*}$ \\
\hline Intere & & & & & & 1 & $.77^{*}$ \\
\hline Abert & & & & & & & 1 \\
\hline
\end{tabular}

\begin{tabular}{|c|c|c|c|c|c|c|c|}
\hline \multicolumn{8}{|c|}{$9^{\circ}$ ano } \\
\hline & $\mathrm{LP}$ & MAT & NSE & Indisci & Exige & Intere & Abert \\
\hline LP & 1 & $.87^{*}$ & $.46^{*}$ & $-.31^{*}$ & $.12 *$ & $.11^{*}$ & $.17^{*}$ \\
\hline Mat & & 1 & $.35^{*}$ & $-.41^{*}$ & $.19^{*}$ & $.17^{*}$ & $.22^{*}$ \\
\hline NSE & & & 1 & $.12^{*}$ & $-.18^{*}$ & $-.18^{*}$ & $-.13^{*}$ \\
\hline Indisci & & & & 1 & $-.36^{*}$ & $-.40^{*}$ & $-.41^{*}$ \\
\hline Exige & & & & & 1 & $.68^{*}$ & $.60^{*}$ \\
\hline Intere & & & & & & 1 & $.88^{*}$ \\
\hline Abert & & & & & & & 1 \\
\hline
\end{tabular}

\begin{tabular}{|c|c|c|c|c|c|c|c|}
\hline \multicolumn{8}{|c|}{$12^{\circ}$ ano } \\
\hline & LP & MAT & NSE & Indisci & Exige & Intere & Abert \\
\hline LP & 1 & $.85^{*}$ & $.38 *$ & $-.25^{*}$ & -.05 & .01 & .03 \\
\hline Mat & & 1 & $.24^{*}$ & $-.36^{*}$ & $.06^{\text {** }}$ & $.10^{*}$ & $.12^{*}$ \\
\hline NSE & & & 1 & $.26^{*}$ & $-.33^{*}$ & $-.23^{*}$ & $-.22^{*}$ \\
\hline Indisci & & & & 1 & $-.42^{*}$ & $-.41^{*}$ & $-.38^{*}$ \\
\hline Exige & & & & & 1 & $.73^{*}$ & $.64^{*}$ \\
\hline Intere & & & & & & 1 & $.92^{*}$ \\
\hline Abert & & & & & & & 1 \\
\hline
\end{tabular}

Fonte: Baseado nos dados do PROEB (2007).

Nota: LP = Língua portuguesa; Mat = matemática; NSE = Nível Sócioeconômico; Indisci $=$ Indisciplina $;$ Exige = Exigência do professor; Intere $=$ Interesse do professor; Abert $=$ Abertura do professor.

*correlação estatisticamente significante $(\mathrm{p}<.01)$.

** correlação estatisticamente significante $(\mathrm{p}<.05)$. 
Os resultados do Quadro 6 mostram que a indisciplina média das escolas foi a variável mais fortemente associada com a proficiência média em matemática em todos os anos ( $r=-.42$ no $5^{\circ}$ ano, $r=-.41$ no $9^{\circ}$ ano; $r=-.36$ no $12^{\circ}$ ano). ${ }^{2}$ Esses dados reforçam a centralidade da indisciplina no aprendizado dos alunos, já que ela mostrou ter uma relação mais forte com a proficiência em matemática do que com o nível socioeconômico médio das escolas. Já a proficiência média em língua portuguesa apresentou uma correlação maior com o NSE médio do que com a indisciplina média das escolas.

Uma hipótese para explicar essa associação mais expressiva da indisciplina com a matemática é que a aquisição do conhecimento matemático seria mais diretamente dependente da intervenção escolar e da existência de um ambiente de aprendizagem mais propício à consecução das atividades de ensino-aprendizagem. Giardinetto (1997), ao discutir a complexidade dos conceitos escolares, defende que a matemática teria um alto grau de complexidade e de distanciamento do cotidiano. Portanto, seria legítimo especular a matemática como sendo mais abstrata e distante da realidade cotidiana do que a língua portuguesa.

Nesse sentido, outros resultados reforçam essa interpretação: em todos os anos, a associação das práticas pedagógicas médias dos professores das escolas é maior com a proficiência média em matemática do que com a proficiência média em língua portuguesa. No $12^{\circ}$ ano, essa questão se torna ainda mais extrema, pois nenhuma prática pedagógica dos professores teve correlação estatisticamente significante com proficiência em língua portuguesa.

Quando analisamos a associação entre a indisciplina média e o NSE médio das escolas, percebemos que as correlações estão entre as mais baixas da tabela em todos os anos (ex: $r=.12$ no $9^{\circ}$ ano). No $5^{\circ}$ ano acontece o caso mais extremo: a correlação entre NSE médio e indisciplina média das escolas não foi estatisticamente significante. Esse dado merece destaque, porque é frequente na literatura educacional e nos depoimentos dos próprios professores a existência de uma associação unilateral entre a origem social dos estudantes e a indisciplina (Silva, 2007). Ao contrário, nossos resultados indicam que a origem social não se constitui como elemento principal para compreender a indisciplina. Contudo, destacamos que os dados com os quais trabalhamos são relativamente homogêneos, uma vez que englobam somente estudantes de escolas públicas. De qualquer modo, esses resultados sinalizam que, se reduzimos a explicação da indisciplina à origem social dos estudantes, corremos o risco de menosprezar o peso dos fatores mais contextuais, como as práticas pedagógicas dos professores.

Como indicado no Quadro 6, as correlações entre indisciplina e as práticas pedagógicas dos professores estão sempre entre os valores mais altos da tabela para todos os anos. Tais resultados sugerem que os professores não são apenas vítimas dos comportamentos de indisciplina dos alunos, mas podem, muitas vezes, devido às suas atitudes ou práticas, constituírem-se em agentes que suscitam, criam ou reforçam tais comportamentos. Ou seja: o trabalho desenvolvido pelos professores em sala de aula impacta a indisciplina (Amado, 1998; Estrela, 1986).

2 Aqui não estamos levando em consideração o valor da correlação entre a proficiência de língua portuguesa e matemática. 
Destacamos também que as correlações entre indisciplina e ambas as proficiências foram mais altas em todos os anos do que as correlações entre as práticas pedagógicas dos professores e ambas as proficiências (mais um argumento a favor da importância da indisciplina). Tomados em conjunto, esses dados sugerem que as práticas pedagógicas dos professores teriam uma influência indireta na proficiência dos alunos, via manejo da indisciplina em sala de aula. Ou seja, professores mais exigentes, interessados e abertos em relação aos alunos criariam um ambiente de aprendizagem mais positivo, o que resultaria em uma melhor aprendizagem.

\section{CONSIDERAÇÕES FINAIS}

Os resultados apresentados nessa pesquisa indicam uma presença marcante de comportamentos de indisciplina em sala de aula. Também apontam uma forte relação entre desempenho escolar e indisciplina ao discutir o atraso escolar e a proficiência dos estudantes em língua portuguesa e matemática. Além disso, merecem destaque a baixa associação entre indisciplina e nível socioeconômico e a forte relação entre as práticas pedagógicas dos professores e a indisciplina. Tomados em conjunto, esses resultados reforçam a relevância e a centralidade da indisciplina no campo educacional.

Contudo, consideramos que são limitações deste trabalho: o número pequeno de itens sobre indisciplina no questionário do PROEB; o fato de os dados sobre as práticas pedagógicas dos professores e a indisciplina serem obtidos exclusivamente por meio das percepções dos alunos.

Nas próximas etapas da pesquisa, aprofundaremos nossas análises por meio da utilização de técnicas estatísticas mais sofisticadas para o trabalho com dados educacionais, como a utilização de regressão multinível e modelagem de equações estruturais multinível.

\section{REFERÊNCIAS}

Afonso, Almerindo Janela. Insucesso, socialização escolar e comportamentos divergentes: uma abordagem introdutória. Revista Portuguesa de Educação, Braga, v. 1, n.2, p. 41-51,1988. . Notas para o estudo sociológico da (in)disciplina escolar na formação dos professores. Revista Portuguesa de Educação, Braga, v. 4, n. 1, p. 119-128, 1991.

Alves, Maria Teresa Gonzaga. Composição do alunado e desempenho da educação básica em Minas Gerais. Relatório de pesquisa apresentado à Fundação de Amparo à Pesquisa de Minas Gerais (FAPEMIG), 2011.

Alves, Maria Teresa Gonzaga; SoAres, José Francisco. Medidas de nível socioeconômico em pesquisas sociais: uma aplicação aos dados de uma pesquisa educacional. Opinião Pública, Campinas, v. 15, n. 1, p. 1-30, 2009.

AmAdo,João da Silva. Interação pedagógica e indisciplina na aula: um estudo de características etnográficas. 1998. Tese (Doutorado em Ciências da Educação) - Universidade de Lisboa, Lisboa, 1998.

\section{Interação pedagógica e indisciplina na aula. Porto: Edições Asa, 2001.}


Uma abordagem da violência escolar. In: I Simpósio Internacional "Juticia y Violência Juvenil: claves para la intervención”, 1., 2004. Anais... Córdoba: Associação Meridianos e Junta da Andaluzia, 2004. p. 143-156.

Aquino, Júlio Gropa (Org.). Indisciplina na escola: alternativas teóricas e práticas. São Paulo: Summus, 1996.

Babbie, Earl. Métodos de pesquisas de survey. Belo Horizonte: Ed. UFMG, 1999.

Cамасно, Luiza Mitiko Yshiguro. As sutilezas das faces da violência nas práticas escolares de adolescentes. Educação e Pesquisa, São Paulo, v. 27, n. 1, p. 123-140, jan./jun. 2001.

CReswell,John. Educational research: planning, conducting, and evaluating quantitative and qualitative research. Upper Saddle River, Nova Jersey: Pearson Merrill Prentice Hall, 2005. Embretson, Susan; Reise, Steven. Item response theory for psychologists. Nova York: Routledge, 2000.

Estrela, Maria Teresa. Une étude sur l'indiscipline en classe. Lisboa: INIC, 1986. Relação pedagógica, disciplina e indisciplina na aula. Portugal: Porto Editora, 1992.

Giardinetto, José Roberto Boettger. O fenômeno da supervalorização do saber cotidiano em algumas pesquisas da educação matemática. 1997. Tese (Doutorado em Educação) - Centro de Educação e Ciências Humanas, Universidade Federal de São Carlos, São Carlos, 1997.

Khine, Myint Swe; Fisher, Darrell. Teacher-student interactions in science classrooms in Brunei. Journal of Classroom Interaction, Houston, v. 38, n. 2, p. 21-28, 2003.

Onetto, Fernando. Criterios de intervención en las problemáticas de convivencia escolar. In: Ruz, Juan R.; Coquelet, Jaime Figueroa (Orgs.). Convivencia escolar y calidad de la educación. Santiago: Maval, 2003. p. 97-112.

Pires, Eurico Lemos. Não há um, mas vários insucessos. Cadernos de Análise Social da Educação, Braga, Universidade do Minho, 1985, p. 11-15.

Prairat, Eirick. Questions de discipline à l'école et ailleurs. 2. ed. Ramonville Saint-Agne: Érés, 2003.

Roure, Susie Amâncio Gonçalves de. Concepçôes de indisciplina escolar e os limites do psicologismo em educação. In: Reunião Anual da Associação Nacional de Pós-Graduação e Pesquisa em Educação, 24., 2001, Caxambu. Anais... Caxambu: ANPEd,2001.Disponível em: <http://www.anped.org.br/reunioes/24/tp1.htm>. Acesso em: 22 out. 2003.

Silva, Luciano Campos da. Disciplina e indisciplina na aula: uma perspectiva sociológica. 2007. Tese (Doutorado em Educação) - Universidade Federal de Minas Gerais, Belo Horizonte, 2007.

Silva, Luciano Campos da; Nogueira, Maria Alice. Indisciplina ou violência na escola. Uma distinção possível e necessária. In: GonçAlves, Luiz Alberto Oliveira; Tosta, Sandra Pereira (Orgs.). A sindrome do medo contemporâneo e a violência escolar. Belo Horizonte: Autêntica, 2008.p. 15-62.

Szenczun, Dorotéa Pascnuki. (In)Disciplina escolar: um estudo da produção discente nos programas de pós-graduação em educação (1981-2001). 2004. Dissertação (Mestrado em Educação) - Universidade Federal do Paraná, Curitiba, 2004. 


\section{SOBRE OS AUTORES}

Luciano Campos da Silva é doutor em educação pela Universidade Federal de Minas Gerais (UFMG). Professor da Universidade Federal de Ouro Preto (UFOP).

E-mail: lucianocampos@ichs.ufop.br

Daniel Abud Seabra Matos é doutor em educação pela Universidade Federal de Minas Gerais (UFMG). Professor da Universidade Federal de Ouro Preto (UFOP).

E-mail: danielmatos@ichs.ufop.br

Recebido em agosto de 2012

Aprovado em maio de 2013 
